\title{
The Coordination Problem in a Structural Model of Peak-Period Congestion: An Experimental Study
}

\author{
YANNICK GABUTHY * \\ BETA, CNRS, University Nancy 2, France \\ MATTHIEU NEVEU \\ GATE, CNRS, University Lyon 2, France \\ LAURENT DENANT-BOEMONT
}

CREM, CNRS, University Rennes 1, France

\begin{abstract}
The purpose of our paper is to generalize the model by Arnott et al. (1990a) to situations with a single origin and destination connected by two routes and to test the analytical results in an experiment with discrete time departure choices. The experimental evidence does not support the theoretical predictions: While the accumulated experience creates significant learning effects which imply a positive evolution of the empirical travel costs towards the equilibrium, the Nash hypothesis is still rejected and the commuting system shows substantial fluctuations until the end of the experiment.
\end{abstract}

\section{Introduction}

Road traffic congestion is one of the greatest problems faced by urban areas. Following Pigou's idea, most economists consider that road pricing promises substantial efficiency gains by reducing congestion or, at least, decreasing the total social cost of traveling for the city: "By shifting some trips to off-peak periods, to routes away from congested facilities, or to higher-occupancy vehicles, or by discouraging some trips altogether, congestion pricing schemes would result in savings in time and operating costs for both private and commercial vehicles, improvements in air quality, reductions in energy

\footnotetext{
* Contact author: BETA, University Nancy 2, 13 place Carnot, F-54035 Nancy, France. E-mail: Yannick.Gabuthy@univ-nancy2.fr. The authors would like to thank Romain Zeiliger for his help on Regate software and anonymous referees for helpful suggestions. We are grateful to the French Ministry of Transport for financial support under the project Predit 2 - Subvention decision $\mathrm{n}^{\circ} 00 \mathrm{MT21}$ "Eléments d'évaluation des politiques de transport: une approche par l'économie expérimentale". This project has been jointly realized in GATE (Lyon, France), LET (Lyon, France), BETA (Nancy and Strasbourg, France), and CREM (Rennes, France).
} 
consumption and improvements in transit productivity.” (Liu, 2004, p.381). Congestion is viewed essentially as a negative externality and economists agree that, when the market mechanism fails to achieve an efficient outcome, price instruments are effective at internalizing external costs. The seminal paper is one by Vickrey (1969) who provided an explicit treatment of the congestion technology and users' behavioral decisions. In this model, a fixed number of commuters have to get from home to work at the same target time. There is a single bottleneck on the road with a fixed capacity, and if the arrival rate at the bottleneck exceeds this capacity a queue develops. The distribution of arrival times is such that it is physically impossible for all commuters to arrive at work exactly on time and to experience no queue. This illustrates a major point in transportation science: Congestion is a dynamic phenomenon and stems from a failure in the commuters' coordination (De Palma, 1992). In the basic model by Arnott et al. (1990a), origin and destination are connected by only one route, and commuters are assumed to have identical travel time cost functions and to face the same arrival time constraints at work. Equilibrium is reached when the queue length over time is such that no driver can reduce his trip cost by changing his departure time. ${ }^{1}$

Following this canonical analysis, our main concern is to derive user equilibrium for a simple network of two routes in parallel (with different tolls and bottleneck capacities) and to test the theoretical predictions by experimental economics. The key question is whether or not users are able to reach a coordinated solution, such as the commuting system converges to a steady state. Our experiment is novel in itself because a coordination problem of this type has not been largely tested and the way the individuals solve this problem is not trivial. In this sense, laboratory experiments serve as powerful tool which can contribute to our understanding of these systems. Schelling argued more than forty years ago that "some essential part of the study of mixed motive games is necessarily empirical." (1960, p.162). His point was that the notion of equilibrium in such games, entailing consistent expectations, leads us naturally to ask how people achieve this "meeting of the minds". Twenty-six years later, after extensive research on game playing, Lucas (1986) concluded that equilibrium theory does not resolve the question of how groups of agents behave in a given interdependent decision situation. Like Schelling before him, Lucas argued that "it is hard to see what we can advance the discussion short of assembling a collection of people, putting them in the situation of interest, and observing what they do.” (1986, p.237). Faced with this challenge, experimenters have devised a large variety of coordination games which are of special interest to economists since they raise the possibility that a group of individuals, or even a whole economy, might become mired in an unfavourable situation. These include, among others, variants of the tacit coordination of decentralized allocation games studied by Meyer et al. (1992) and Ochs (1990), and the market entry games investigated by Erev and Rapoport (1998), Rapoport et al. (1998), and Sundali et al. (1995). ${ }^{2}$ Several of these studies have reported coordination success whereas most have reported coordination failure.

\footnotetext{
${ }^{1}$ Notice that the analysis has been generalized to allow for differences in commuters (Arnott et al., 1989) and to situations with a single origin and destination connected by more than one route (Arnott et al., 1990b). More recently, McDonald (1995) and Verhoef et al. (1996) develop a two-link static equilibrium model to examine the second-best one-route congestion pricing in the presence of an untolled alternative. Verhoef (2002) extended the single-period second-best congestion pricing model to a general road network. See Liu (2004) for a survey of this body of literature.

${ }^{2}$ See Cooper $(1999)$ and Ochs $(1995,1999)$ for surveys.
} 
The experimental literature on traffic congestion reports also important results about coordination behavior. A number of simulation experiments were performed to explore dynamic properties of traffic commuting systems under alternative behavioral mechanisms operating at the individual user level (Mahmassani et al., 1986; Mahmassani and Chang, 1985, 1986; Mahmassani and Herman, 1987). The principal feature that distinguishes these works from our conventional microeconomic perspective is that they are not limited to a utility-maximizing model of individual behavior, but instead seek behaviorally realistic heuristics and decision rules. The authors investigate the convergence problem by using the boundedly rational user equilibrium which is achieved when all users are satisfied with their current travel choices (Mahmassani and Chang, 1987). More precisely, it is considered that a commuter will switch his choice from one period to the next only if the perceived benefit from doing so exceeds a threshold. For departure time choice, Mahmassani and Chang (1987) define the threshold in terms of an indifference band about the preferred arrival time. In other words, a commuter will adjust his departure time whenever his experienced schedule delay (that is the difference between the preferred arrival time and actual arrival time) exceeds some tolerable value corresponding to his individual indifference band. The experiments based on the bounded rationality paradigm report evidence that user equilibrium is typically not unique and the reached equilibrium (if any) depends on the adjustment process, while this process and its magnitude depend themselves on each individual's preferences, information availability, and recallable experiences with the facility. Some recent studies on traffic congestion have also been produced in the strict experimental economics literature. The first paper by Schneider and Weimann (2004) aims to test the single-route model by Arnott et al. (1990a). They report evidence in support of equilibrium departure time in their first but not second experiment and show that road pricing is an effective instrument at internalizing external congestion costs. Selten et al. (2004) focus on route choice in a generic two-route scenario, which already has been investigated in literature (Iida et al., 1992). It can be seen that there is no convergence to the theoretical equilibrium and substantial fluctuations persist until the end of the experiment. The last analysis, conducted by Rapoport et al. (2005), investigates the empirical relevance of the Braess paradox (Braess 1968). ${ }^{3}$ The authors show that forty periods were required to reach equilibrium in a route-choice-only game on a three-link network, while the commuting decisions did not converge to the equilibrium even after eighty periods on a more complex network. In this context, our experimental setup diverges from the previous papers in several ways:

(1) We treat departure time choices as discrete rather than continuous and then calibrate the experimental travel cost function following some empirical studies about time cost values (De Palma and Fontan, 2001; De Palma and Rochat, 1995). The parameter values are chosen so that queuing does not occur in the Nash equilibrium which allows us to focus on whether subjects coordinate their choices in order to avoid congestion and minimize their travel costs.

(2) To our knowledge, it is the first attempt to study experimentally departure time decisions on a two-link network, dealing with road pricing and analyzing the effect of tolling regime on traffic congestion. Schneider and Weimann (2004) consider only

\footnotetext{
${ }^{3}$ The Braess paradox consists of showing that, in equilibrium, adding a new link that connects two routes running between a common origin and a common destination may raise the travel cost for each network user.
} 
departure time choice in a single-route model, while the experiment by Selten et al. (2004) and Rapoport et al. (2005) are not concerned with endogenous departure time but with route choice.

(3) Our experimental setup implements larger groups (that is individuals playing together) and a higher number of players (almost 100 subjects). The main experimental results are the following. First, the empirical evidence does not support the approach used in our model in the sense that individuals do not follow the equilibrium departure distribution. Second, the evidence shows that route split is significantly sensitive to the tolling regime: The choice of the tolled route is negatively affected by the price level, however a larger fraction of commuters choose the tolled road than predicted by theory. Considering the performance and dynamic properties of the commuting system, the experimental results support that experience creates learning effects which imply a trend of the observed travel costs towards the Nash equilibrium, even if this equilibrium is never reached and the system shows a wide range of oscillation until the end of the experiment. The available information may play a major role to explain such a coordination failure.

The remainder of the paper is organized as follows. Section 2 outlines the proposed modeling framework and theoretical predictions as an experimental benchmark. Section 3 presents the experimental design, especially experimental conditions of the congestion game and calibration of payoff functions for players. Section 4 exposes the experimental results on departure times and route choices. Finally, Section 5 concludes by discussing these results in the light of transportation literature.

\section{A model with two routes and discrete departure time choices}

Our approach is based on the model of Arnott et al. (1990a). However, the authors consider continuous departure times while this variable has to be discrete in experimental games. That is the reason why we develop a two-route choice model with discrete time.

We consider that $n$ identical individuals have to get from home to work at a common target time $t^{*}$, with $N=\{1, \ldots \ldots, n\}$ and $n \geq 2$. Each commuter has to choose simultaneously a departure time $t$ and a road $h$, defining the following strategy spaces:

$$
t \in T=\left\{-\infty . \ldots ., t^{*}-1, t^{*}, t^{*}+1, \ldots \ldots,+\infty\right\} \text { and } h \in H=\{A, B\}
$$

Travel is not congested except at a single bottleneck which at most $s_{j}$ cars can traverse per unit of time, with $j=\{A, B\}$. If the arrival rate at the bottleneck exceeds $s_{j}$ a queue develops. Therefore, the capacity constraint is a flow constraint, while the queue discipline is first-come, first-served. We consider that road A has no toll and a low bottleneck capacity, while road B has a positive toll and a higher capacity (that is $s_{B}>s_{A}$ and $p_{B}>p_{A}$ $=0) .{ }^{4}$ One could consider that the paths from home to workplace consist in a city street

\footnotetext{
${ }^{4}$ The simplest policy entails the application of a time-invariant or uniform toll. Furthermore, since only the difference between the tolls affects route choices, the toll on road A can be set to zero without loss of generality. Notice however that there is no intrinsic reason to impose the toll on the route with higher capacity given that we consider a model with inelastic travel demand.
} 
(road A) and a freeway (road B). Furthermore, capacity on route A might be limited by a bridge or tunnel while the flow on path B might be limited by an access ramp. In taking his decision, each individual faces a trade-off between his travel time, schedule delay and toll. User equilibrium is reached when no commuter can reduce his cost by changing either his departure time or route, taking all others commuters' choices as given. It turns out that equilibrium can be determined in two steps: First solving for the departure rate on each road and second computing the number of drivers on each route.

\subsection{Benchmark case}

As a benchmark, we first solve for user equilibrium and characterize the social optimum in the absence of road B. This analysis is useful as a baseline to derive the second step of the equilibrium determination. In this context, let $D(t)$ and $R(t)$ be the queue lengths measured at the beginning and at the end of the period respectively. ${ }^{5}$ The addition of a driver at time $t$ increases the queue length not just at this time, but at next times as well.

$$
R(t)=\max \{0, D(t-1)-s\}
$$

Therefore, defining $N(t)$ as the number of commuters who leave home at time $t$, we obtain:

$$
D(t)=R(t)+N(t)
$$

Then, an individual's travel time $T^{v}(t)$ equals queue length at the time he joins the queue divided by bottleneck capacity. Without affecting results of interest, we set that an individual expends a minimum uncongested travel time equals to one unit. That is, he does not arrive at work immediately upon leaving home.

$$
T^{v}(t)=\max \{1, \quad\}
$$

Let $\alpha$ be the cost of one unit of travel time and $\beta(\gamma)$ the cost of arriving one unit of time early (late). ${ }^{6}$ Then the cost of a trip from home to work for a commuter leaving home at time $t$ is:

$$
C(t)=\alpha T^{v}(t)+\beta \max \left\{0, t^{*}-T^{v}(t)-t\right\}+\gamma \max \left\{0, T^{v}(t)+t-t^{*}\right\}
$$

In choosing when to leave home, individuals face a trade-off between travel time and schedule delay. Those arriving very early or late experience substantial schedule delay cost but little congestion; those arriving on time experience maximum congestion. ${ }^{7}$ Equilibrium obtains when no individual can reduce his trip cost by altering his departure time, taking all other drivers' departure times as given. We focus attention on the pure-strategy Nash

\footnotetext{
${ }^{5}$ Here, queue length is defined as the number of cars in the queue.

${ }^{6}$ For simplicity, $\alpha, \beta$ and $\gamma$ are assumed to be the same for everyone (that is individuals are assumed to be homogeneous). Furthermore, the travel cost may be nonlinear or exhibit discontinuities, however we follow common practice in assuming linearity.

${ }^{7}$ Following convention, individuals are assumed to have full information about the departure time distribution.
} 
equilibrium which seems to be a natural concept to employ in this context. ${ }^{8}$ The equilibrium departure rate is stated in Proposition 1.

Proposition 1. The equilibrium departure rate is constant and equal to the bottleneck capacity throughout the rush hour $\left\{t^{*}-K, \ldots, t^{*}-1\right\}$, if and only if $(K-1) \beta<\gamma$, where $K$ $=(N / S)$ is the length of the rush hour.

\section{Proof . See Appendix 1.}

The intuition behind this proposition is the following. The equilibrium rate of departure is constant and equal to $s$ throughout the rush hour if the relative cost of late arrival $\gamma / \beta$ is sufficiently high. Under this condition, individuals who depart at the beginning of the rush hour are not incited to switch from $t^{*}-K$ in order to leave home later and decrease their schedule delay costs of arriving early at the expense of arriving late.

\subsection{The social optimum}

The social optimum is determined by minimizing the sum of travel time and schedule delay costs. To eliminate queuing while minimizing schedule delay costs, the departure rate is maintained at $s$ throughout the rush hour. Since this condition is also true of user equilibrium, the timing of the rush hour and the departure distribution are the same as in equilibrium. ${ }^{9}$ Denoting variables corresponding to the social optimum (equilibrium) with a superscript $o(e)$, aggregate travel time costs (TTC), schedule delay costs (SDC), and travel costs $(T C)$ are given by ${ }^{10}$

$$
\begin{aligned}
& T T C^{o}=T T C^{e}=N \alpha \\
& S D C^{o}=S D C^{e}=\frac{N(N-s) \beta}{2 s} \\
& T C^{o}=T C^{e}=N \alpha+\frac{N(N-s) \beta}{2 s}
\end{aligned}
$$

\subsection{Extension to two routes}

The analysis is now extended to a network with two roads in parallel in order to study the impact of the tolling regime on the individuals' behavior. As explained above, the equilibrium conditions presented in Proposition 1 keep the same characteristics for each route. However, the reasons which explain route selection have to be specified.

\footnotetext{
8 "Pure strategies appear to be more realistic than mixed strategies, since most individuals prefer a routine to leave home at the same time" (Arnott et al., 1993, p.164).

${ }^{9}$ The equilibrium departure distribution is congruent with the optimal distribution for two reasons. First, our theoretical departure time set is designed such that there is no queuing in equilibrium. Indeed, our parameters $K=N / s, \beta$ and $\gamma$ are related by the equilibrium condition $(K-1) \beta<\gamma$. Therefore, a modification in the number of individuals $(N)$ and/or the commuters' characteristics $(\beta, \gamma)$ implies a modification in the rush hour. Second, these parameter values insure that the equilibrium and optimal departures begin and end at the same time.

${ }^{10}$ These costs are independent of $\gamma$ because the start and end of the rush hour are independent of $\gamma$. However, they depend on $\alpha$ because each individual expends a minimum uncongested travel time equals to one unit.
} 
Proposition 2. In equilibrium, a commuter chooses the freeway if and only if $\beta\left(t_{B}-t_{A}\right)>$ $p_{B}$, where $t_{j}$ is the most recent time at which the commuter could depart without incurring delay on road $j(j=A, B)$.

\section{Proof. See Appendix 2.}

The intuition behind this result is the following. A commuter chooses the freeway as long as payoff resulting from a lower travel cost on this route is higher than the toll. Furthermore, since the uniform toll adds a constant fee to the trip on road B, it does not alter the departure pattern and diverts only drivers from one route to another.

\section{Experimental design}

We first provide a general description of the design and second explain the parameters and theoretical predictions in details. The experiments were run in the GATE experimental laboratory with 96 subjects and consisted in 12 sessions, with each session comprising 15 repetitions (called rounds). The participants were randomly recruited from a subject pool of students of several universities and the graduate school of management (Lyon, France). All of them were inexperienced in transport experiments and no subject participated in more than one of the sessions. ${ }^{11}$ Upon arrival, participants were randomly assigned to visually isolated computers. The GATE experimental laboratory has privacy conditions sufficient to assure that participants could not observe each others' decisions. At the beginning of each session, instructions were distributed and read aloud (see Appendices 3 and 4). Clarifying questions were asked and answered privately. Then we asked the participants to fill in a control questionnaire in order to check for understanding. Only after all questions had been correctly answered, the experiment started.

At the beginning of each round, each subject chooses simultaneously a departure slot and a road in the following available strategy spaces:

$$
T=\left\{-9,-8,-7,-6,-5,-4,-3,-2,-1, t^{*}=0,1,2,3,4\right\} \text { and } H=\{A, B\}
$$

The parameters have been ascribed the following values: 12 sessions of 8 participants were run (that is $N=8$ ) and the bottleneck capacity of road A (B) is assumed to be $s_{A}=1$ $\left(s_{B}=2\right)$. Following the theoretical analysis, the congestion is a dynamic phenomenon: The addition of a user at a given slot increases the queue length not just at this slot, but at other slots as well. For instance, if four participants choose slot -3 and route $B$, they expend two units of time (that is slots -3 and -2) to arrive at destination. Assuming that two other participants choose slot -2 on road B, they will spend two units of time in the queue because two cars are already waiting in line. This numerical example shows that subjects who depart at the same time are assumed to arrive at the same time even though they would traverse the bottleneck sequentially rather than simultaneously. After all subjects

\footnotetext{
${ }^{11}$ The fact that participants were students (and therefore inexperienced drivers) is clearly a limitation of our experiment and the role of this limitation on the experimental results is discussed in Section 5. However, the recruitment of real commuters would have been a much more complex and costly process that would have probably eliminated this problem but not all the limitations created by the experimental environment.
} 
had entered their decisions in the computers, the resulting departure distribution, path dispatching and individual payoffs were calculated. After each round, every participant was shown the following information on his computer screen: His decision (that is road and departure time), his travel time, his arrival slot, the number of players who chose his departure slot and road, and his payoff. At the beginning of a round, each player gets an initial endowment of 500 Points, which is reduced by the schedule delay cost and travel time cost incurred in the round. The cost of one unit of travel time is $\alpha=16$ and the cost of arriving one unit of time early (late) is $\beta=5(\gamma=40)$. Since $N / s_{A}=8$ and $N / s_{B}=4$, these parameter values ensure that the equilibrium condition stated in Proposition 1 is satisfied. ${ }^{12}$

All amounts were given in a fictitious currency (Points), with conversion into Euros at a rate of 500 Points $=12 €$ upon completion of the session. The total payment was the average of the single payoffs of the fifteen periods plus a $4 €$ show-up fee for participating. The experiment was computerized using the Regate software (Zeiliger, 2000). A partnermatching protocol was placed into effect, according to which group assignment remained constant throughout the session. In other words, the eight participants interact together in the fifteen consecutive rounds. This protocol enables obtaining more independent observations than a stranger protocol where the eight participants would be re-matched such that the same eight individuals would do not interact together in two consecutive periods. In this context, much more subjects would be necessary to get a sufficient number of independent observations to conduct nonparametric tests. ${ }^{13}$ On average, each session lasted one hour, excluding payment of subjects.

The basic question in our study is whether the empirical evidence supports the theoretical predictions and the toll value has an impact on the individuals commuting behavior: Do the commuters solve the coordination problem in order to avoid a prohibitive travel time cost and what is the impact of the toll level on the individuals' coordination? Therefore, we consider a first treatment where $p_{B}=4$ (Low-toll, called P4 treatment) and a second one where $p_{B}=8$ (High-toll, called P8 treatment), which give the following equilibrium predictions to be tested.

We can state that the most efficient tolling regime is the low one. The toll level influences the commuters' behavior in a natural way: a relatively high toll induces individuals to choose the city street (instead of the freeway) which in turn forces them to leave home earlier in order to avoid a traffic congestion (which increases schedule delay and results in a less efficient outcome).

\footnotetext{
${ }^{12}$ Furthermore, De Palma and Rochat (1995) found a ratio $\beta / \alpha=0.3$ and a ratio $\gamma / \alpha=2.7$. More recently, De Palma and Fontan (2001) found empirical evidence for $\beta / \alpha=0.5$ and $\gamma / \alpha=2.5$. We decided to be very near to these studies, choosing in our experiment $\beta / \alpha=0.3125$ and $\gamma / \alpha=2.5$. An additional justification is that experimental players have to be able to clearly discriminate the elements of the payoff function. In this context, it is important to implement high differences between schedule delay costs and travel time cost to make cost evaluation of individual choice easier for subjects.

${ }^{13}$ Furthermore, the dynamic properties of the commuting system and the potential learning effects could not be analyzed in such a random-matching protocol given that group assignment would not remain constant throughout the session.
} 


\begin{tabular}{|l|l|l|l|}
\hline \multicolumn{2}{|l|}{ Experimental parameters } & Experimental conditions \\
\hline Strategy spaces & $\begin{array}{l}\left\{-9,-8, \ldots, t^{*}=0 \ldots, 3,4\right\} \\
\{A, B\}\end{array}$ & Number of rounds & 15 \\
\hline $\begin{array}{l}\text { Number of } \\
\text { individuals }\end{array}$ & $N=8$ & Matching protocol & Partner \\
\hline Bottleneck capacities & $\begin{array}{l}s_{A}=1 \\
S_{B}=2\end{array}$ & $\begin{array}{l}\text { Experimental } \\
\text { software }\end{array}$ & Regate \\
\hline $\begin{array}{l}\text { Cost of one unit of } \\
\text { travel time }\end{array}$ & $\alpha=16$ & Initial endowment & 500 Points \\
\hline $\begin{array}{l}\text { Cost of arriving one } \\
\text { unit of time early }\end{array}$ & $\beta=5$ & Conversion rate & 500 Points $=12 €$ \\
\hline $\begin{array}{l}\text { Cost of arriving one } \\
\text { unit of time late }\end{array}$ & $\gamma=40$ & $4 €$ \\
\hline $\begin{array}{l}\text { Toll cost } \\
p_{B}=4 \text { points } \\
p_{B}=8 \text { points }\end{array}$ & & \\
\hline
\end{tabular}

Table 1: Overview of experimental design

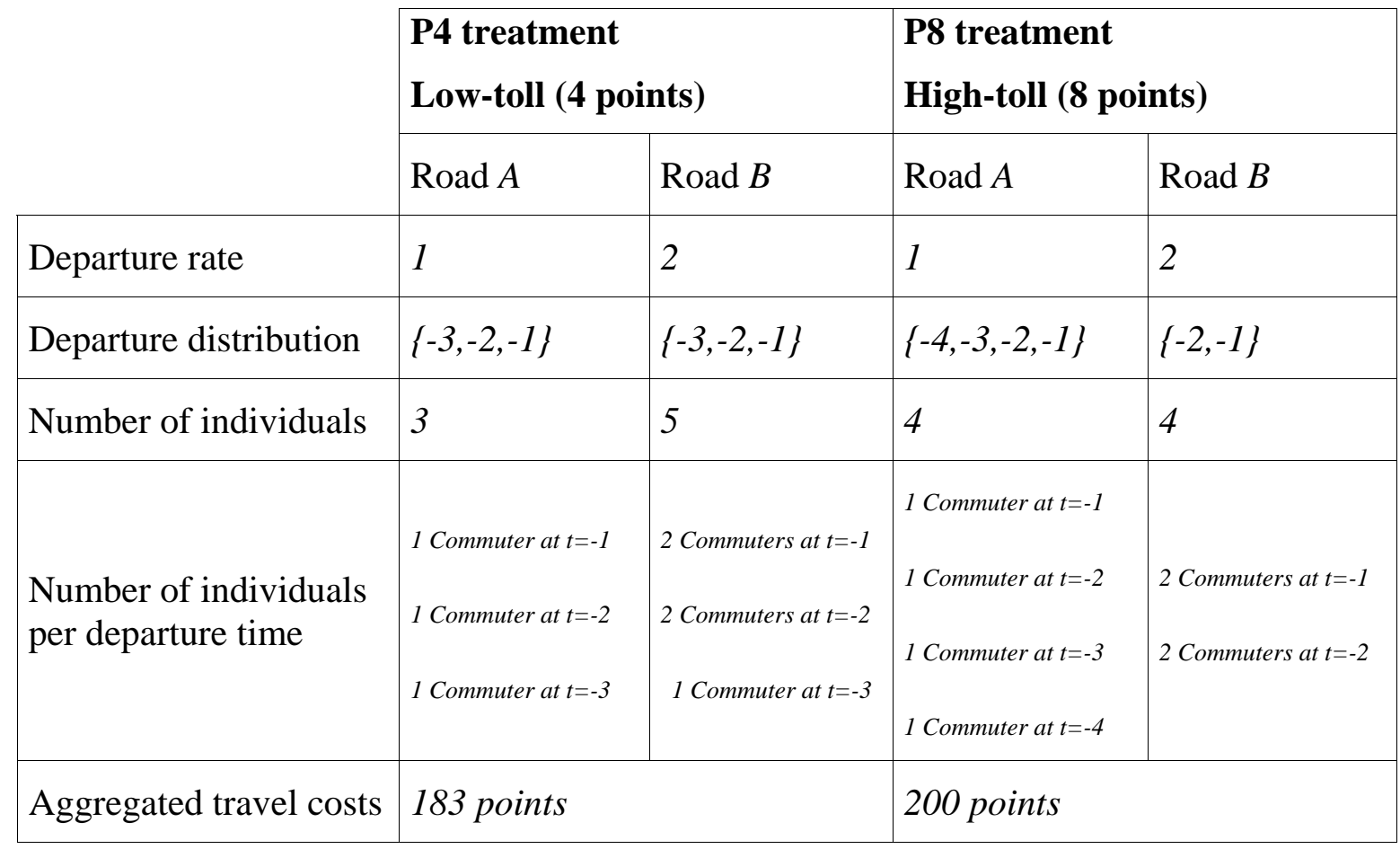

Table 2: Overview of equilibrium predictions 


\section{$4 \quad$ Experimental results}

Table 3 summarizes some descriptive statistics of the data from the 12 sessions. Displayed in this table are means, standard deviations and ranges for departure, arrival and travel times for each treatment and each road. In addition, route split is presented for each treatment.

\begin{tabular}{|c|c|c|c|c|c|c|c|c|c|}
\hline Treatment & $\begin{array}{l}\text { Number } \\
\text { of group }\end{array}$ & $\begin{array}{l}\text { Group } \\
\text { size }\end{array}$ & Road & $\begin{array}{l}\text { Toll } \\
\text { cost }\end{array}$ & $\begin{array}{l}\text { Frequency } \\
\text { of Road } \\
\text { choice }\end{array}$ & & $\begin{array}{l}\text { Departure } \\
\text { Times }\end{array}$ & $\begin{array}{l}\text { Arrival } \\
\text { Times }\end{array}$ & $\begin{array}{l}\text { Travel } \\
\text { Times }\end{array}$ \\
\hline \multirow[t]{9}{*}{ P4 } & \multirow[t]{9}{*}{6} & \multirow[t]{9}{*}{8} & \multirow[t]{3}{*}{ A } & \multirow[t]{3}{*}{0} & \multirow[t]{3}{*}{$35.42 \%$} & Mean & -2.45 & -0.95 & 1.50 \\
\hline & & & & & & Std Deviation & 1.6 & 1.90 & 0.66 \\
\hline & & & & & & Min ; Max & $-8 ; 4$ & $-7 ; 5$ & $1 ; 3$ \\
\hline & & & \multirow[t]{3}{*}{ B } & \multirow[t]{3}{*}{4} & \multirow[t]{3}{*}{$64.58 \%$} & Mean & -2.39 & -1.15 & 1.23 \\
\hline & & & & & & Std Deviation & 1.28 & 1.47 & 0.49 \\
\hline & & & & & & Min ; Max & $-9 ; 1$ & $-8 ; 2$ & $1 ; 3$ \\
\hline & & & \multirow{3}{*}{$\begin{array}{l}\text { Global } \\
(\mathrm{A}+\mathrm{B})\end{array}$} & & & Mean & -2.41 & -1.08 & 1.32 \\
\hline & & & & & & Std Deviation & 1.40 & 1.64 & 0.57 \\
\hline & & & & & & Min ; Max & $-9 ; 4$ & $-8 ; 5$ & $1 ; 3$ \\
\hline \multirow[t]{9}{*}{ P8 } & \multirow[t]{9}{*}{6} & \multirow[t]{9}{*}{8} & \multirow[t]{3}{*}{ A } & \multirow[t]{3}{*}{0} & \multirow[t]{3}{*}{$43.33 \%$} & Mean & -2.47 & -0.73 & 1.74 \\
\hline & & & & & & Std Deviation & 1.29 & 1.62 & 0.83 \\
\hline & & & & & & Min ; Max & $-7 ; 1$ & $-6 ; 3$ & $1 ; 4$ \\
\hline & & & \multirow[t]{3}{*}{ B } & \multirow[t]{3}{*}{8} & \multirow[t]{3}{*}{$56.67 \%$} & Mean & -2.13 & -0.84 & 1.28 \\
\hline & & & & & & Std Deviation & 1.08 & 1.22 & 0.48 \\
\hline & & & & & & Min ; Max & $-9 ; 0$ & $-8 ; 1$ & $1 ; 3$ \\
\hline & & & \multirow{3}{*}{\multicolumn{3}{|c|}{$\begin{array}{l}\text { Global } \\
(\mathrm{A}+\mathrm{B})\end{array}$}} & Mean & -2.28 & -0.79 & 1.48 \\
\hline & & & & & & Std Deviation & 1.19 & 1.41 & 0.69 \\
\hline & & & & & & Min ; Max & $-9 ; 1$ & $-8 ; 3$ & $1 ; 4$ \\
\hline
\end{tabular}

Table 3: Overview of experimental observations

\subsection{Departure times}

We first analyze departure time choices made by subjects. These results are computed over all the rounds for each road and each treatment. Figure 1 displays the mean departure times for each treatment and road over the fifteen rounds.

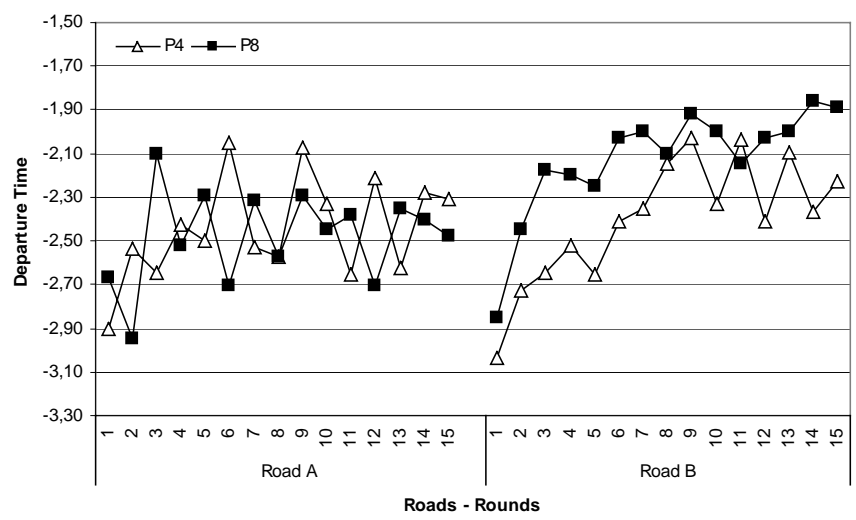

Figure 1: Departure times 
The nonparametric statistics mentioned in the next paragraph indicate that the road pricing level may influence the departure time decisions. If two commuters use a tolled road, commuter using low toll road (treatment P4) chooses to start earlier than commuter choosing high toll road (treatment P8). This behavioral difference is not observed when commuters use free road. We can sum up this result as follow. Commuters who accept to pay a high toll want to depart closer to the target time $\left(t^{*}\right)$. In return, a commuter choosing the free road does not pay toll and therefore depart at the same times whatever the toll value.

On road A, the average departure time (standard deviation) is equal to -2.45 (1.60) in P4 treatment and -2.47 (1.29) in P8 treatment. This difference between treatments is not significant by a Wilcoxon-Mann-Whitney test $\left(\mathrm{W}_{\mathrm{x}}=39.5, \mathrm{p}<0.56\right) .{ }^{14}$ Commuters leave home at the same time on road A whatever the toll level. On road B, the average departure time (standard deviation) equals -2.39 (1.28) in P4 and -2.13 (1.08) in P8. This difference is statistically significant by a Wilcoxon-Mann-Whitney test $\left(\mathrm{W}_{\mathrm{x}}=29.5, \mathrm{p}<0.0779\right)$. Therefore, commuters leave home later on road B in the high-toll treatment.

We test whether the empirical distribution of departures follow the equilibrium distribution. In Figures 2 and 3 the empirical and theoretical distributions are plotted for each treatment and route. Even if most of the empirical departure times belong to the equilibrium departure distribution, a significant number of commuters depart earlier than the theoretical results predict. This result shows that the individuals fail to coordinate on the Nash equilibrium. Nevertheless, this deviation does not prevent commuters to travel without experiencing high traffic congestion.

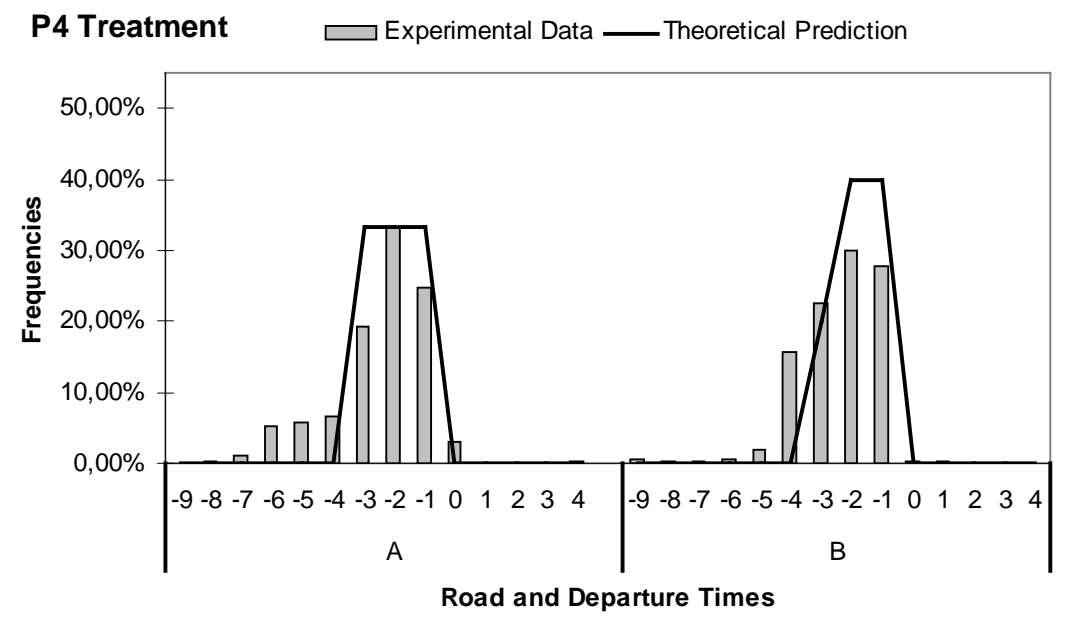

\section{Figure 2: Departure times. Experimental data and theoretical prediction, P4 treatment}

In P4 treatment, the modal departure choice is equal to -2 on road $A$ and $77.25 \%$ of the empirical departure times belong to the equilibrium departure distribution $\{-3 ;-1\}$. On road $\mathrm{B}$, the mode is equal to -2 and $80.43 \%$ of the departures belong to the equilibrium distribution $\{-3 ;-1\}$. For each road we compare empirical and theoretical distributions by a

\footnotetext{
${ }^{14}$ All reported tests are one-tailed.
} 
Kolmogorov-Smirnov two-sample test. Results show that the empirical distribution of departures is statistically different from the Nash distribution (Road A: $\mathrm{p}<0.06701$; Road B: $p<0.04962)$. In P8 treatment, the mode is equal to -3 and $92 \%$ of the empirical departure times belong to the equilibrium departure distribution $\{-4 ;-1\}$ on road $A$. On road $\mathrm{B}$, the mode equals -2 and $68.63 \%$ of the times belong to the equilibrium distribution $\{-2 ;-1\}$. A Kolmogorov-Smirnov two-sample test shows that this difference between empirical and theoretical distribution is statistically significant (Road A: $\mathrm{p}<0.07699$; Road $\mathrm{B}: \mathrm{p}<0.0529)$. Therefore, there is evidence that players do not play Nash.

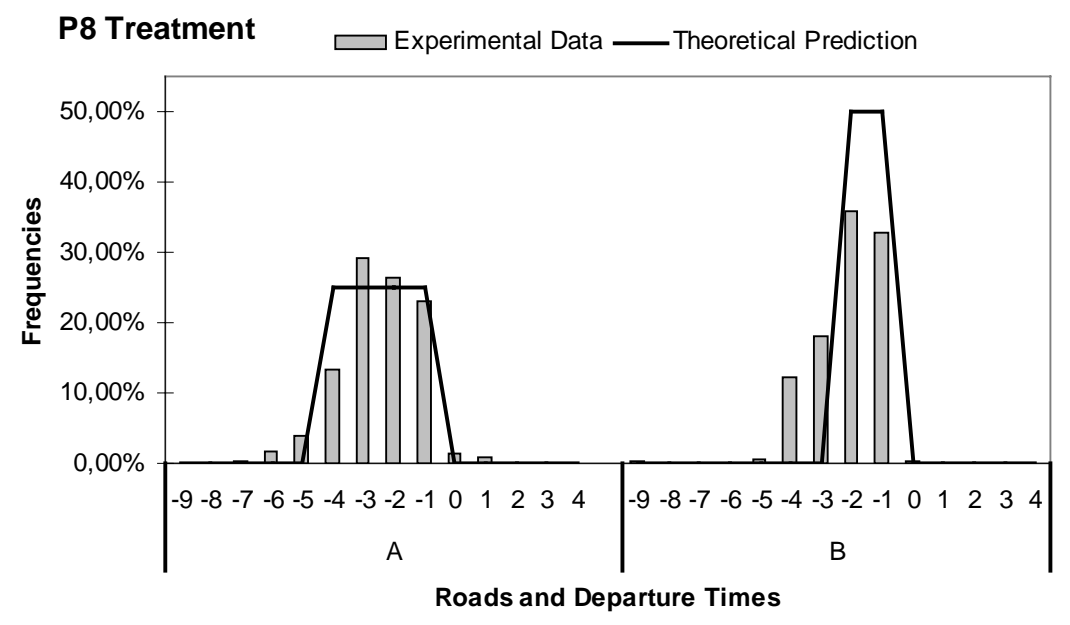

Figure 3: Departure times. Experimental data and theoretical prediction, P8 treatment

\subsection{Road choices}

We study now the impact of tolling regime (that is 4 points and 8 points) on the route choices and compare the experimental route split to the Nash one. Figure 4 illustrates route split for each treatment over the fifteen periods.

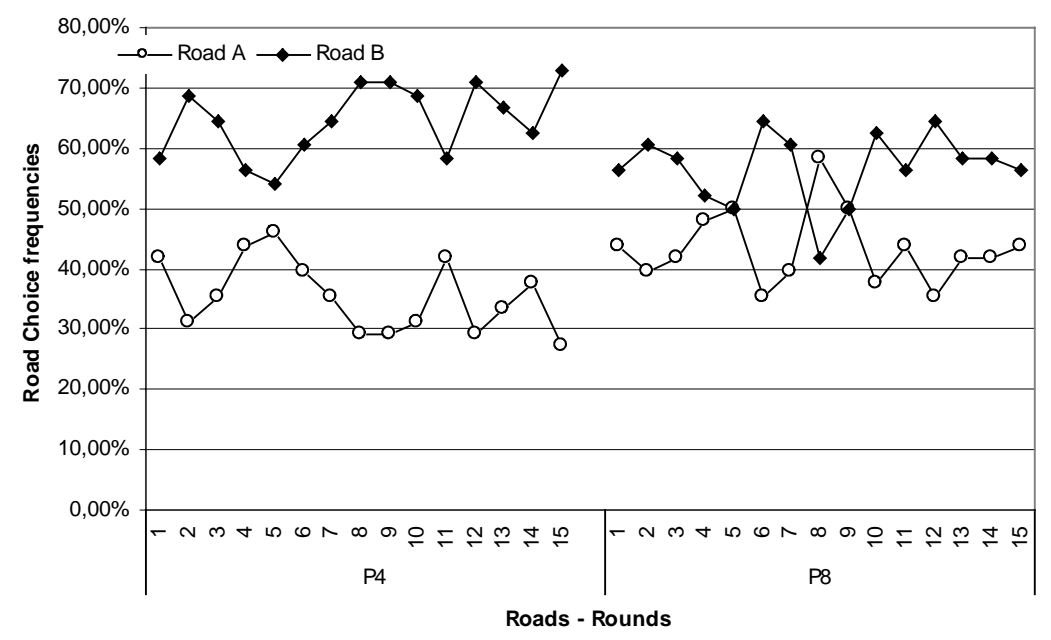

Figure 4: Roads choices 
In P4 treatment (P8 treatment), 64.58\% (56.67\%) of route choices correspond to road $\mathrm{B}$. We realize a Chi-square test to determine whether the observed dispatching of players between the two roads is similar to the Nash one (i.e. 3/8 of individuals on road A and 5/8 on road B in P4, 1/2 of individuals on each road in P8). We observe that the empirical route decisions do not follow the theoretical prediction. The experimental players choose road $\mathrm{B}$ more often than Nash players (P4: $\chi^{2}=10.05, \mathrm{p}<0.0015$ and P8: $\chi^{2}=12.8, \mathrm{p}<0.0003$ ). Furthermore, comparing the route split between treatments shows that commuters' choices are significantly sensitive to the tolling regime: The choice of road B is negatively affected by the toll value $\left(\chi^{2}=9.12, \mathrm{p}<0.0025\right)$. In other words, despite the fact that the overall choice of the tolled route is discouraged by the price level, a larger fraction of users choose the freeway than predicted by theory and the same is true for both treatments. The intuition behind this result may be that subjects perceived a larger travel time savings from taking the freeway. ${ }^{15}$

\subsection{Traffic congestion and arrival times}

\subsubsection{Traffic congestion}

The congestion level corresponds to the travel time variable $\left(T^{v}(t)\right)$. In our analysis this variable can take one of the following values: $1,2,3$ or $4 . T^{v}(t)=1$ corresponds to a situation with no congestion, while $T^{v}(t)=4$ reveals the route is highly crowded. However, to simplify data analysis, we restrict attention to two congestion levels: No congestion (when $T^{v}(t)=1$ ) and Congestion (when $T^{v}(t)=\{2.3 .4\}$ ). Figure 5 illustrates congestion distribution for each road and each treatment.

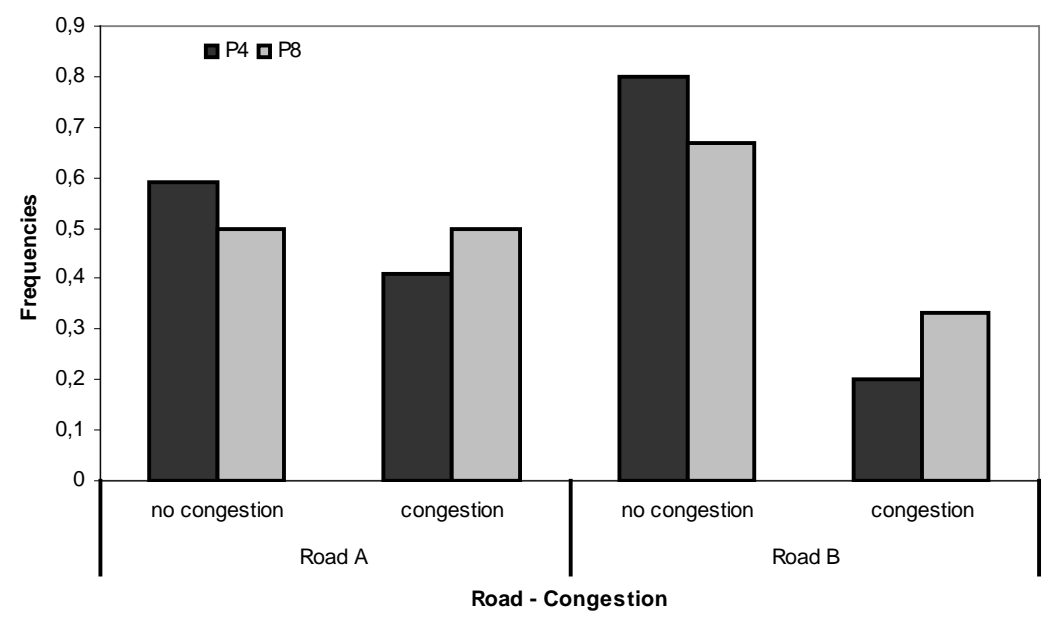

\section{Figure 5: Congestion level according to treatment and road selected}

On road A, modal value of travel times equals 1 in both treatments. In P4 treatment (P8 treatment), 59.2\% (47.4\%) of the individuals have traveled without congestion. On road B,

\footnotetext{
${ }^{15}$ Revealed preference studies using US data on tolled roads have obtained high estimates of the value of time and one explanation for this is that drivers may overestimate their time savings by taking the tolled lane. For example, Lam and Small (2001) measure values of time and reliability using 1998 data on actual travel behavior in a real pricing context (State Route 91, Orange County, California).
} 
the modal value also equals 1 but this no congestion situation gathers $80 \%$ (72.8\%) of the commuters in P4 (P8). Furthermore, we have to precise that the individuals have never traveled in an overcrowded situation such that $T^{v}(t)=4$.

We first analyze the impact of toll level on the congestion occurrence. In P4 treatment (P8 treatment), 72.64\% (61.81\%) of commuters decisions were without congestion. This difference is statistically significant by a Chi 2 test $\left(\chi^{2}=18.68, \mathrm{p}<1.54 \mathrm{E}-5\right)$. A low toll cost improves coordination both on departure times and road choice which leads to less congestion. On each road, we now compare occurrence or absence of congestion between treatments. Results show that there is less congestion on the two lanes in P4 treatment. A Chi 2 test shows that the difference is statistically significant (Road A: $\chi^{2}=4.3238$, $\mathrm{p}<0.0375$; Road B: $\chi^{2}=19.85, \mathrm{p}<8.355 \mathrm{E}-6$ ).

This last result corroborates our previous results on coordination. When toll cost is high, commuters refuse to use the available equilibrium departure times set and gather themselves close to the target time $\left(t^{*}\right)$. This behavior leads to an overcrowded situation. Notice that, in both treatments, using positive toll road improves commuters' coordination in the sense that more than $72 \%$ of travels do not experience any congestion.

\subsubsection{Arrival times}

We now study the distribution of arrival times. Arrival time is equal to departure time plus travel time. Figure 6 shows the mean arrival times on each road and for each treatment over the fifteen rounds.

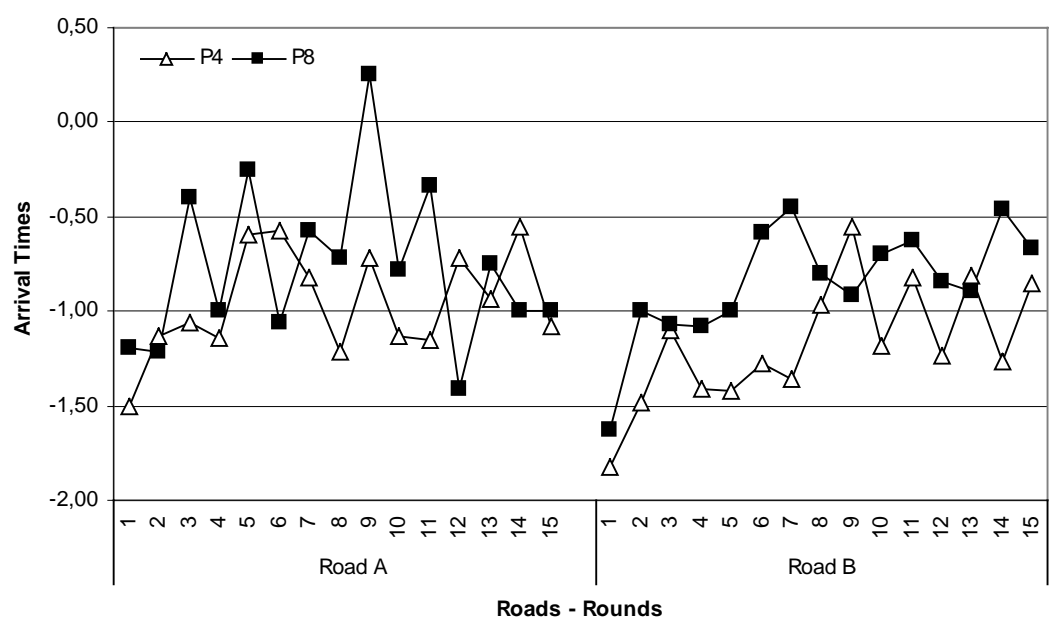

\section{Figure 6: Arrival times}

On free road, modal arrival time value is equal to 0 (that is target time) for both treatment. In P4 treatment (P8 treatment), 27.5\% (23.7\%) of arrival times are equal to 0 , $51 \%(51.6 \%)$ correspond to early arrivals and $21.5 \%$ (24.7\%) correspond to late arrivals. On this road, the mean arrival time (standard deviation) is -0.95 (1.90) in P4, and -0.73 (1.62) in P8. This difference is not statistically significant by a Wilcoxon Mann Whitney test $\left(\mathrm{W}_{\mathrm{x}}=35, \mathrm{p}<0.2944\right)$. Commuters using the free road arrived at the same time on average, whatever the value of the toll.

On positive toll road, modal arrival time value is also equal to 0 (that is target time) for both treatments. In P4 treatment (P8 treatment), 26.9\% (37\%) of arrival times are equal to $0,63.7 \%(52.5 \%)$ correspond to early arrivals and $9.4 \%(10.5 \%)$ correspond to late 
arrivals. On the tolled road, the mean arrival time (standard deviation) is -1.15 (1.47) in $\mathrm{P} 4$, and -0.84 (1.22) in P8. This difference is statistically significant by a Wilcoxon Mann Whitney test $\left(\mathrm{W}_{\mathrm{x}}=30, \mathrm{p}<0.0898\right)$. So commuters using tolled road arrived closer to the target time when the toll cost is high than when it is low.

\subsection{Evolution and performance of the commuting system}

Performance of the commuting system is analyzed through the aggregated travel cost which is a relevant criterion as it takes into account both departure time and road choices. As mentioned in Table 2, the equilibrium aggregated travel cost is equal to 183 in P4 treatment and 200 in P8 treatment. Therefore, the equilibrium average cost (for each subject) is 22.88 in $\mathrm{P} 4$ and 25 in P8. The experiment results show a mean cost (standard deviation) of 37.13 (24.02) in P4 treatment and 41.01 (24.63) in P8 treatment. This difference is not statistically significant by a Wilcoxon Mann Whitney test $\left(\mathrm{W}_{\mathrm{x}}=36.5\right.$, $\mathrm{p}<0.3793$ ), which implies that the tolling regime does not influence the efficiency of the commuting system by improving subjects coordination.

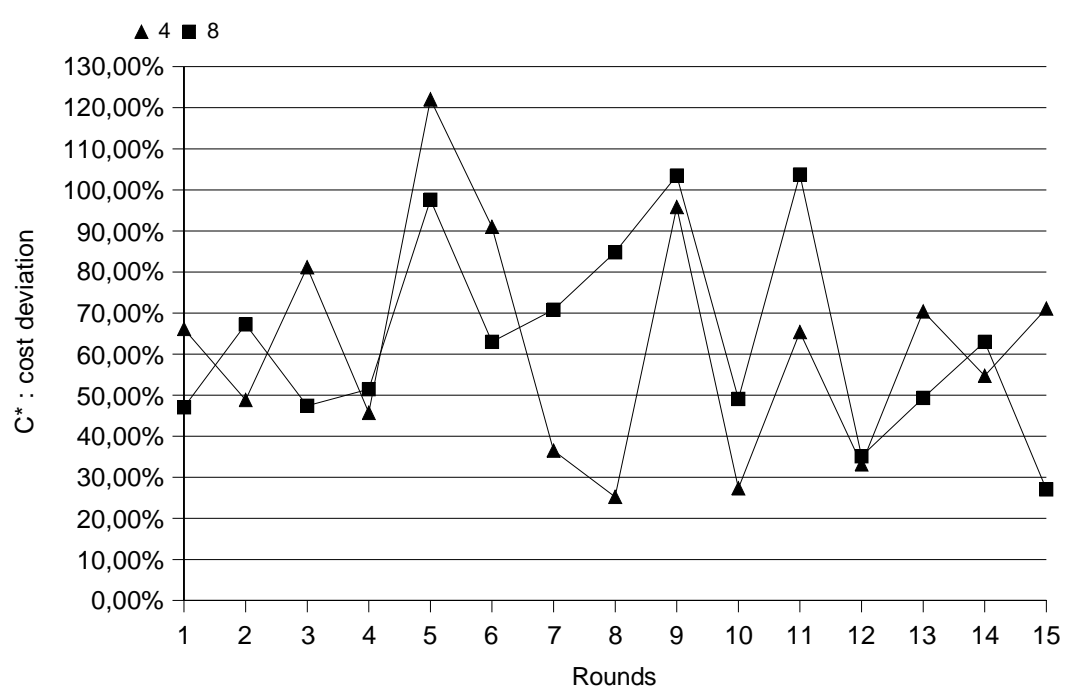

Figure 7: Evolution of the travel cost

The determination of the aggregated travel cost is also performed to explore the evolution and dynamic properties of the commuting system. A key question is whether or not this system converges to equilibrium such as subjects are able to coordinate in the sense of minimizing the travel costs (from round to round). In order to compare the observed behavior with the predictions, we build an index of deviation which measures the difference between the mean observed travel cost $\left(\mathrm{C}^{\mathrm{obs}}\right)$ and the theoretical (that is equilibrium) travel cost $\left(\mathrm{C}^{\text {th }}\right)$ :

$$
C^{*}=
$$


The evolution of this index over the course of the experiment is reported in Figure 7. A positive value of $\mathrm{C}^{*}$ implies that participants incur, on average, a travel cost higher than the equilibrium prediction and the commuting traffic system fails to achieve an efficient outcome. ${ }^{16}$ A Change Point test is performed in each treatment in order to determine whether a breaking point occurs in the evolution of $\mathrm{C}^{*}$ over the fifteen rounds of the experiment. In P4 treatment (P8 treatment), a statistically significant trend reversal is reached at round 6 (round 11) with $\mathrm{W}=60$ and $\mathrm{p}<0.0951(\mathrm{z}=1.83, \mathrm{p}<0.0336)$. In $\mathrm{P} 4$, the mean costs (standard deviation) before round 6 and after round 7 are respectively 40.22 (6) and 35.07 (5.24). This result induces a 13\% decrease in travel cost. In P8, the mean costs (standard deviation) before round 11 and after round 12 are respectively 42.86 (5.38) and 35.91 (3.43), which induces a 16\% decrease in travel cost.

We now focus the analysis on each set of rounds (that is 1 to 6 and 7 to 15 for P4 treatment; 1 to 11 and 12 to 15 for P8 treatment) to know how departure time and road choices have changed to improve coordination between subjects.

We first analyze the departure time decisions in $\mathrm{P} 4$ treatment. On the first set of rounds (that is 1 to 6), the mean departure time (standard deviation) is -2.45 (1.38), while it is -2.3 (1.37) in the second set (that is 7 to 15). This decrease is statistically significant with a Wilcoxon Mann Whitney test $(\mathrm{Wx}=29, \mathrm{p}<0.06)$. We consider the subjects' road decisions in order to compare their stability in each set of rounds. In the first six periods, $40 \%$ of the route decisions correspond to road A. This fraction decreases to $32 \%$ in the next periods. This difference is statistically significant with a Chi 2 test $\left(\chi^{2}=3.35, \mathrm{p}<0.07\right)$. Given that a larger fraction of subjects choose road B in the second set of rounds compared to the first one, we analyze whether they switch route more often in the first set. In the first six periods of the game, $72 \%$ of the subjects' decisions were to stay on the same road (A or B) from one period to the next, while this fraction increased to $77 \%$ in the last nine periods. This difference is not statistically significant with a Chi 2 test $\left(\chi^{2}=2.1, \mathrm{p}<0.15\right)$.

Contrary to P4 treatment, the subjects' departure decisions in P8 are not modified from one set of rounds to the other one. On the first set of rounds (that is 1 to 11), the mean departure time (standard deviation) is -2.3 (1.13), while it is -2.16 (1.07) in the second set (that is 12 to 15). This difference is not statistically significant with a Wilcoxon Mann Whitney test $(\mathrm{Wx}=32, \mathrm{p}<0.15)$. Considering the subjects' road decisions, the results state that $44.3 \%$ of the route decisions correspond to road A in the first eleven periods, while this fraction declines to $40.6 \%$ in the next periods. However, this difference is not statistically significant with a Chi 2 test $\left(\chi^{2}=0.64, \mathrm{p}<0.42\right)$. Nevertheless, it is shown that commuters improve their coordination by staying individually more on the same route: In the first eleven periods of the game, $74 \%$ of the subjects' decisions were to stay on the same road from one period to the next, while this proportion increased to $85 \%$ in the last four periods. This difference is statistically significant with a Chi 2 test $\left(\chi^{2}=6.77, p<0.01\right)$.

\section{$5 \quad$ Discussion of the results and concluding remarks}

Following Section 4.4., the results show a positive evolution of the observed travel cost towards the Nash equilibrium and, while this trend is small, it indicates significant learning

\footnotetext{
${ }^{16}$ Indeed, as mentioned in Section 2.2, the equilibrium travel cost corresponds to the social optimum such as no congestion occurs. Therefore, any higher value implies a loss of efficiency induced by a coordination failure.
} 
effects over time that lead the subjects to improve their coordination. These improvements occur at different points in the experiment depending on the treatment (on the first part of the experiment for P4 treatment and on the second part for P8 treatment), which implies that the learning process is faster in the low toll situation. However, as shown in Figure 7, there are substantial fluctuations around the means until the end of the experiment as subjects continue to switch routes and change their departure times over iterations of the stage game. In other words, the commuting system continuously shows a wide range of oscillation without converging to equilibrium or any steady state (as mentioned in Sections 4.1 and 4.2). ${ }^{17}$ Given the rather small number of participants in each session (that is eight subjects) and the partner-matching protocol used in the experiment, this no convergence situation may seems to be surprising in the sense that the eight participants interact together in all iterations of the game and would be expected to achieve a tacitly collusive or coordinated solution. ${ }^{18}$ One intuitive explanation for this coordination failure is the small number of iterations we consider in the experimental game. The experiment was limited to fifteen rounds and this is probably too short for subjects to get accustomed to the situation and develop a sufficient learning (or adaptive) process leading them to a perfect coordination on a stable situation.

This hypothesis seems all the more plausible because the subjects have perfect information in our experiment and it is not clear whether more information is beneficial. ${ }^{19}$ The response of road users to information is still an open question (Ben-Akiva et al. 1991). Mahmassani and Liu (1999) report evidence that more time is required to reach an equilibrium when subjects have full information than when they have only limited information. Indeed, several behavioral phenomena may negate some of the beneficial effects of improved information. First, commuters confronted with too much information may become oversaturated in the sense that information processing becomes too difficult and users develop simple heuristics to solve the problem (Gigerenzer et al. 1999). Second, drivers may also overreact to information and thereby cause additional fluctuations. Overreaction is likely to take place if commuters fail to consider or underestimate the potential responses of the other drivers (Ben-Akiva et al. 1986, Fujii 1986). Finally, information tends to reduce the variations among commuters because it increases uniformity of perceptions of network conditions around the true values. As a result a greater number of drivers may select the best alternatives (from the individual point of view) and consequently drivers with similar preferences will tend to concentrate on the same routes during the same departure times. Thus, more information could potentially generate higher levels of traffic congestion. ${ }^{20}$ Furthermore, the subjects of our experiment were students in France who may not have been experienced drivers and therefore not representative of commuters who regularly travel by car under congested conditions. The

\footnotetext{
${ }^{17}$ The overall system is considered to reach steady state when users stop adjusting their departure time and road decisions.

${ }^{18}$ Nevertheless, notice that our experimental design allows the participants to be independent as their identities are not revealed. This mitigates the reputation effects and the influence that a particular player may have on the decisions of the other group members.

${ }^{19}$ As mentioned in Section 3, participants received a feedback with the entire history of both travel times and road choices after each period.

${ }^{20}$ Ben-Akiva et al. (1991) precise that the most useful type of information to a driver faced with travel choices is reliable predictive information. However, the provision of such information is extremely difficult. In congested networks, predictive information must be based on projected traffic conditions which are dependent on the ways in which commuters will respond to the information.
} 
way the subject updates his travel information is based on his experience accumulated from round-to-round experiment as well as his own historic experience as a driver. We conjecture reasonably that the efficiency with which the information provided by the commuting system is used depends on the personal experience as a motorist.

It is not however obvious if the evolution of commuting behavior would converge to an equilibrium state with further continuation of the experiment. The experimental evidence is mixed. Schneider and Weimann (2004) report evidence in support of equilibrium departure time in their first but not second experiment comprising 50 iterations of the stage game. Rapoport et al. (2005) show that 40 periods were required to reach equilibrium in a routechoice-only game on a three-link network. They also report that the travel choices did not converge to the equilibrium even after 80 trials on a more complex network, although they steadily moved in this direction. Despite increasing the number of trials five-fold, Selten et al. (2004) found no convergence to pure-strategy equilibrium. Rather, they observed considerable fluctuations around the means and attributed these fluctuations to the multiplicity of equilibria: "The multiplicity of pure-strategy equilibria poses a coordination problem which may be one of the reasons for non-convergence and the persistence of fluctuations” (Selten et al., 2004, p.4). In other words, dynamic systems would be prone to oscillate without converging to an equilibrium. This is consistent with the results of Helbing (2004), Mahmassani et al. (1986), Rapoport et al. (2005), and Schneider and Weimann (2004). Furthermore, experiments conducted by Meyer et al (1992) and Ochs (1990) indicate that coordination failures and persistent fluctuations can be observed in other repeated coordination environments, such as decentralized market games. ${ }^{21}$ The common finding of both of these experiments is that a distribution consistent with a purestrategy equilibrium is not an absorbing state in repeated games with a stationary set of inexperienced subjects. Sustained perfect coordination requires a consistency of beliefs among agents as to what other agents in the market will do, and the experiments indicate that the mutual confidence needed to sustain perfect coordination is not easy to build and can be easily shaken by perturbations in the market. Such processes involving individual decision making, human interaction, and learning in a dynamic environment are complex and much more work needs to be done before we have a complete and robust understanding about them. Further empirical exploration of the coordination behavior in commuting systems, particularly the convergence to and stability of equilibria, remain an important research direction in transportation science.

\section{$6 \quad$ References}

Arnott, R., A. de Palma and R. Lindsey (1989) "Schedule Delay and Departure Time Decisions with Heterogeneous Commuters,” Transportation Research Record, 1197: 5667.

Arnott, R., A. de Palma and R. Lindsey (1990a) “Economics of Bottleneck,” Journal of Urban Economics, 27: 111-130.

\footnotetext{
${ }^{21}$ A decentralized market consists of several locations at which trades can take place and a set of agents, each of whom must decide at which location to attempt to trade without having the benefit of prior information on where other agents are going.
} 
Arnott, R., A. de Palma and R. Lindsey (1990b) "Departure Time and Route Choice for the Morning Commute,” Transportation Research, Part B, 24: 209-228.

Arnott, R., A. de Palma and R. Lindsey (1993) "A Structural Model of Peak-Period Congestion: A Traffic Bottleneck with Elastic Demand," American Economic Review, 83: 161-179.

Ben-Akiva, M., A. de Palma and P. Kanaroglou (1986) "Dynamic Model of Peak Period Traffic Congestion with Elastic Arrival Rates,” Transportation Science, 20: 164-181.

Ben-Akiva, M., A. de Palma and I. Kaysi (1991) "Dynamic Network Models and Driver Information Systems,” Transportation Research, Part A, 25: 251-266.

Braess, D. (1968) “Uber ein Paradoxon der Verkhersplanung," Unternehmensforschung, 12: 258-268.

Cooper, R.D. (1999) Coordination in Games: Complementaries and Macroeconomics. Cambridge University Press: Cambridge.

De Palma, A. (1992) "A Game-Theoretic Approach to the Analysis of Simple Congested Networks,” American Economic Review, 82: 494-500.

De Palma, A. and C. Fontan (2001) “Choix Modal et Valeur du Temps en Ile-de-France,” Working Paper n²001-20, THEMA, University of Paris 10.

De Palma, A. and D. Rochat (1995) "Etude Empirique du Choix de l'Heure de Départ au Travail,” Working Paper n9522, THEMA, University of Paris 10.

Erev, I. and A. Rapoport (1998) "Coordination, “Magic," and Reinforcement Learning in a Market Entry Game,” Games and Economic Behavior, 23: 145-176.

Fujii, M. (1986) “The CACS Project and Now: Dynamic Route Guidance or the Final Target," Paper presented at the $65^{\text {th }}$ Annual Meeting of the Transportation Research Board, Washington, DC.

Gigerenzer, G., P.M. Todd and ABC Research Group (1999) Simple Heuristics that Make us Smart. Oxford University Press: Oxford.

Helbing, D. (2004) "Dynamic Decision Behaviour and Optimal Guidance through Information Services: Models and Experiments,” in M. Schreckenberg \& R. Selten (ed.), Human Behaviour and Traffic Networks, Berlin: Springer Verlag.

Iida, Y., T. Akiyama and T. Uchida (1992) "Experimental Analysis of Dynamic Route Choice Behavior,” Transportation Research, Part B, 26: 17-32.

Lam, T.C. and K.A. Small (2001) "The Value of Time and Reliability: Measurement from a Value Pricing Experiment,” Transportation Research, Part E, 37: 231-251. 
Liu, L.N. (2004) "Multi-period Congestion Pricing Models and Efficient Tolls in Urban Road Systems," Review of Network Economics, 3: 381-391.

Lucas, R.E. Jr. (1986) Adaptative Behavior and Economic Theory. In R.M. Hogarth \& M. W. Reder (eds), Rational Choice: The Contrast between Economics and Psychology, University of Chicago Press: Chicago.

McDonald, J.F. (1995) "Urban Highway Congestion: An Analysis of Second-best Tolls," Transportation, 22: 353-369.

Mahmassani, H. and G.L. Chang (1985) "Dynamic Aspects of Departure Time Choice Behavior in a Commuting System: Theoretical Framework and Experimental Analysis," Transportation Research Record, 1037: 88-101.

Mahmassani, H. and G.L. Chang (1986) "Experiments with Departure Time Choice Dynamics of Urban Commuters,” Transportation Research, Part B, 20: 297-320.

Mahmassani, H. and G.L. Chang (1987) "On Boundedly Rational User Equilibrium in Transportation Systems,” Transportation Science, 21: 89-99.

Mahmassani, H.S., G.L. Chang and R. Herman (1986) "Individual Decisions and Collective Effects in a Simulated Traffic System,” Transportation Science, 20: 258-271.

Mahmassani, H. and R. Herman (1987) "Interaction of Trip Decisions and Traffic Systems Dynamics,” European Journal of Operational Dynamics, 30: 304-317.

Mahmassani, H. and Y.H. Liu (1999) "Dynamics of Commuting Decision Behaviour under Advanced Traveller Information Systems,” Transportation Research, Part C, 7: 91-107.

Meyer, D.J., J. van Huck, R. Battalio and T. Saving (1992) "History's Role in Coordinating Decentralized Allocation Decisions: Laboratory Evidence on Repeated Binary Allocation Games,” Journal of Political Economy, 100: 292-316.

Ochs, J. (1990) “The Coordination Problem in Decentralized Markets: An Experiment," Quarterly Journal of Economics, 105: 545-559.

Ochs, J. (1995) "Coordination Problems," in J.H. Kagel and A.E. Roth (ed.), The Handbook of Experimental Economics. Princeton University Press: Princeton.

Rapoport, A., T. Kugler, S. Dugar and E. Gisches (2005) "Choice of Routes in Congested Traffic Networks: Experimental Tests of the Braess Paradox,” Working Paper, Department of Management and Policy, University of Arizona.

Rapoport, A., D.A. Seale, I. Erev and J.A. Sundali (1998) "Equilibrium Play in Large Group Market Entry Games,” Management Science, 44: 129-141.

Schelling, T. (1960) The Strategy of Conflict. Harvard University Press: Cambridge, Massachusetts. 
Schneider, K. and J. Weimann (2004) "Against all Odds: Nash Equilibria in a Road Pricing Experiment," in M. Schreckenberg \& R. Selten (ed.), Human Behaviour and Traffic Networks, Springer Verlag: Berlin.

Selten, R, M. Schreckenberg, T. Chmura, T. Pitz, S. Kube, S.F. Hafstein, R. Chrobok, A. Pottmeier and J. Wahle (2004) "Experimental Investigations of Day-to-Day Route Choice Behaviour and Network Simulations of Autobahn Traffic in Nord Rhine-Westphalia," in M. Schreckenberg \& R. Selten (ed.), Human Behaviour and Traffic Networks, Springer Verlag: Berlin.

Small, K.A. (1982) “The Scheduling of Consumer Activities: Work Trips,” American Economic Review, 72: 467-479.

Sundali, J.A., A. Rapoport and D.A. Seale (1995) "Coordination in Market Entry Games with Symmetric Players," Organizational Behavior and Human Decision Processes, 64: 203-218.

Verhoef, E. T. (2002) "Second-best Congestion Pricing in General Networks: Heuristic Algorithms for Finding Second-best Optimal Toll Levels and Toll Points,” Transportation Research, Part B, 36: 707-729.

Verhoef, E.T., P. Nijkamp and P. Rietveld (1996) "Second-best Congestion Pricing: The Case of an Untolled Alternative,” Journal of Urban Economics, 40: 279-302.

Vickrey, W. (1969) “Congestion Theory and Transport Investment,” American Economic Review, 59: 251-260.

Zeiliger, R. (2000) "A presentation of Regate, Internet Based Software for Experimental Economics,” GATE, http://www.gate.cnrs.fr/ zeiliger/regate/RegateIntro.ppt

\section{$7 \quad$ Appendix}

\section{Appendix 1. Proof of Proposition 1}

In accordance with empirical results (Small, 1982), we assume that $\gamma>\alpha>\beta$. Furthermore, we have to distinguish three cases depending on the relative number of commuters.

1. $N \leq$ s. All the commuters can leave home at the same departure time and no queue develops. Each individual chooses the departure time $\tilde{t}$ which minimizes its travel cost:

$$
\tilde{t}=\operatorname{argmin} C(t)=\alpha T^{v}(t)+\beta \max \left(0, t^{*}-T^{v}(t)-t\right)+\gamma \max \left(0, T^{v}(t)+t-t^{*}\right)
$$

It is straightforward to show that $\tilde{t}=t^{*}-1$ since $C(\tilde{t})=\alpha$, that is individuals incur only the minimum uncongested travel cost. 
2. $s<N \leq 2 s$. In this case, $s$ commuters leave home at $t^{*}-1$ while $N$-s individuals choose the departure time $t^{*}-2$ if and only if $C\left(t^{*}-2\right)<C\left(t^{*}-1\right)$, that is $\beta<\alpha+\gamma$.

3. $N>2$ s. The commuters need $K$ departure times to arrive at work with no congestion, with $K=[N / s]$ (where [N/s] denotes the least integer greater than or equal to $N / s$ ). This Nash equilibrium is reached if no commuter can reduce his trip price by changing his departure time, taking all others commuters' choices as given. Therefore, the first departure time in the rush hour is $t^{*}-K$ and we consider two potentially profitable deviations:

and

$$
\begin{gathered}
C\left(t^{*}-K\right)<C\left(t^{*}-X\right) \text {, with } X \in\{1, \ldots, K-1\} \Leftrightarrow(K-1) \beta<\alpha+\gamma \\
C\left(t^{*}-K\right)<C\left(t^{*}\right) \Leftrightarrow(K-1) \beta<\gamma
\end{gathered}
$$

If condition (13) is satisfied, then condition (12) holds.

\section{Appendix 2. Proof of Proposition 2}

The equilibrium condition is intuitive. Let $t_{A}=t^{*}-t^{\prime}{ }_{A}\left(t_{B}=t^{*}-t^{\prime}{ }_{B}\right)$, the most recent time at which there is no queue on route $A(B)$. In other words, $t_{j}$ is the less costly departure time on road $j$ while $t^{\prime}{ }_{j}$ is the number of periods from $t_{j}$ to $t^{*}(j=\{A, B\})$. Hence, the commuter chooses road $B$ as long as:

$$
\begin{aligned}
C^{B}\left(t_{B}\right)<C^{A}\left(t_{A}\right) & \Leftrightarrow \alpha+\left(t^{\prime}{ }^{-}-1\right) \beta+p_{B}<\alpha+\left(t^{\prime}{ }^{-}-1\right) \beta \\
& \Leftrightarrow \beta\left(t_{B}-t_{A}\right)>p_{B}
\end{aligned}
$$

\section{Appendix 3. Instructions (English translation)}

(Upon arrival, each participant draws a card in an envelope indicating the name of the computer terminal in the laboratory. When all participants are seated, the experimenter thanks them for coming, distributes the instruction sheets and reads them aloud.)

You will be participating in an experiment in which you can earn money. The amount of your earnings will depend on your decisions and those of the other participants. Participants make their decisions individually in front of their computers.

During the experiment:

$>$ You and seven other anonymous participants constitute a group of eight.

$>$ The experiment consists of 15 repetitions, called periods.

$>$ You remain with the same group over the 15 periods.

The following instructions are the same for all participants.

\section{- The rules}

In each period, you have to travel from a starting point to an arrival point. In order to do this, you have to choose:

- A departure time. The time schedule in which you can choose your departure time is given by 14 slots: 


$$
-9,-8,-7,-6,-5,-4,-3,-2,-1,0 \text { (target slot), 1, 2, 3, } 4 .
$$

The optimal arrival slot is slot 0 (called, target slot) for all participants.

- A road. You can either choose a city street (road A) or a freeway (road B).

In each period, your payoff will be computed in the following way: At the beginning of each period, you receive 500 points as an initial endowment. However, you may have to bear a travel cost which depends on the following elements:

1- Your travel time (that is, the time you need to get from the starting point to the arrival point): For each slot you are on a road, your payoff will be reduced by $\alpha=16$ points. If you do not get into a traffic congestion, your arrival slot equals 1 plus your departure slot. Therefore, we assume that there is a fixed travel time equals to one slot.

2- Your arrival slot (that is, your departure slot plus your travel time):

$\checkmark$ Your payoff will be reduced by $\beta=5$ points for each slot you arrive early (before the target slot).

$\checkmark$ Your payoff will be reduced by $\gamma=40$ points for each slot you arrive late (after the target slot).

3- The toll : Your payoff will be reduced by 4 [8] points if you choose the freeway (road $\mathrm{B})$, while the city street (road A) is not costly. ${ }^{22}$

$\alpha, \beta, \gamma$ and the toll keep the same values throughout the 15 periods.

\footnotetext{
${ }^{22}$ Instructions between « [] » are for P8 treatment only.
} 


\section{- How your payoffs will be computed?}

Your travel time depends on two parameters: the number of participants who are on the road when you depart and the capacity of the road.

The number of participants who are on the road when you depart is defined by:

The number of participants who choose your departure slot $+$

The number of participants who are still on the road when you depart

The capacity of the road is defined by the number of participants who can pass per slot without a queue developing. Each road has a different capacity: the capacity of road A is one participant per slot, while the capacity of road B is two participants per slot. The roads' capacities keep the same values throughout the 15 periods.

In the following tables, we present your travel time depending on the number of participants who choose your departure slot and the number of participants who are still on the road when you depart.

\section{Table A}

\begin{tabular}{|c|c|c|c|c|c|c|c|c|c|}
\hline \multirow{2}{*}{$\begin{array}{l}\text { Your travel } \\
\text { time on road A }\end{array}$} & & \multicolumn{8}{|c|}{ Number of participants who choose the same departure slot (you are included) } \\
\hline & & 1 & 2 & 3 & 4 & 5 & 6 & 7 & \multirow{2}{*}{$\begin{array}{l}8 \\
8\end{array}$} \\
\hline \multirow{8}{*}{$\begin{array}{l}\text { Number of } \\
\text { participants who } \\
\text { are still on the } \\
\text { road when you } \\
\text { depart }\end{array}$} & 0 & 1 & 2 & 3 & 4 & 5 & 6 & 7 & \\
\hline & 1 & 2 & 3 & 4 & 5 & 6 & 7 & 8 & \\
\hline & 2 & 3 & 4 & 5 & 6 & 7 & 8 & & \\
\hline & 3 & 4 & 5 & 6 & 7 & 8 & & & \\
\hline & 4 & 5 & 6 & 7 & 8 & & & & \\
\hline & 5 & 6 & 7 & 8 & & & & & \\
\hline & 6 & 7 & 8 & & & & & & \\
\hline & 7 & 8 & & & & & & & \\
\hline
\end{tabular}

Table B

\begin{tabular}{|ll|llllllll|}
\hline Your travel & & \multicolumn{8}{|c|}{ Number of participants who choose the same departure slot (you are included) } \\
time on road B & & 1 & 2 & 3 & 4 & 5 & 6 & 7 & 8 \\
\hline Number of & 0 & 1 & 1 & 2 & 2 & 3 & 3 & 4 & 4 \\
participants who & 1 & 1 & 2 & 2 & 3 & 3 & 4 & 4 & \\
are already on the & 2 & 2 & 2 & 3 & 3 & 4 & 4 & & \\
road when you & 3 & 2 & 3 & 3 & 4 & 4 & & \\
depart & 4 & 3 & 3 & 4 & 4 & & & \\
& 5 & 3 & 4 & 4 & & & & \\
& 6 & 4 & 4 & & & & & \\
& 7 & 4 & & & & & & \\
& & & & & & & & &
\end{tabular}


Examples : The following examples explain you the way your payoff will be calculated by the computer terminal. Suppose the following arbitrary specified decisions:

\section{$1^{\text {st }}$ example.}

In your group, you are the only participant to choose the departure slot « -2 » on road A and no other participant are still on road A at slot «-2 ».

Your travel time is :

Your arrival slot is:

Your payoff is :

\section{1 slot (see table A)}

« -1 »:You arrive 1 slot early.

(arrival slot $=$ departure slot + travel time $=«-2 »+« 1 »=\ll \mathbf{- 1} »)$

$479=500-(1 * 16)-(1 * 5)$

Payoff $=$ Endowment $-($ Travel time $* \alpha)-($ Time early $* \beta)$

\section{$2^{\text {nd }}$ example.}

In your group, you are the only participant to choose the departure slot « -2 » on road B and no other participant are still on road B at slot « $-2 »$.

Your travel time is :

Your arrival slot is:

Your payoff is :

\section{1 slot (see table B)}

« -1 »: You arrive 1 slot early.

(arrival slot = departure slot + travel time $=«-2 »+\langle 1 »=«-\mathbf{1} »)$

$475=500-(1 * 16)-(1 * 5)-4$

$[471=500-(1 * 16)-(1 * 5)-8]$

Payoff $=$ Endowment $-($ Travel time $* \alpha)-($ Time early $* \beta)-$ Toll

$3^{\text {rd }}$ example.

In your group, 4 participants (you are included) choose the departure slot « -2 » on road A and 2 other participants are still on road A at slot « -2 ».

Your travel time is:

Your arrival slot is:

Your payoff is :

\section{6 slots (see table $A)$}

« 4 »: You arrive 4 slots late.

(arrival slot $=$ departure slot + travel time $=\langle-2 »+« 6 »=« 4 »)$

$244=500-(6 * 16)-(4 * 40)$

Payoff $=$ Endowment $-($ Travel time $* \alpha)-($ Time late $* \gamma)$

\section{- How will you take your decisions?}

Three areas are available on your computer screen. ${ }^{23}$

The simulation area: Before entering your final choice, this area gives you the opportunity to take fictitious decisions (departure slot and road) in order to know the different payoffs according to the possible travel times. You can use it whenever you want throughout the 15 periods.

\footnotetext{
${ }^{23}$ See Appendix 4.
} 
The decision area : This area must be used to enter your final decision (departure slot and road). This decision will determine your payoff for the period. You have to click on the OK button in order to confirm your decision. You have to be careful because, after that, you are not allowed to modify your decision.

The information area : After each period, you will get the following information (which is available throughout the 15 periods):

- The road you have chosen.

- The departure slot you have chosen.

- Your travel time.

- Your arrival slot.

- The number of participants who chose your departure slot and road (you are included).

- Your payoff.

\section{- Your earnings}

At the end of the experiment, you will be paid privately according to the following rules: Your earnings are equal to the average of your payoffs over the 15 periods. Points will be converted into Euros at a rate of 500 points $=12 €$. In addition, you will receive a $4 €$ lump-sum payment for participation. If you have any question regarding these instructions, please raise your hand. We will try to clarify them privately. Before beginning the experiment, we will ask you several questions to check your understanding of these instructions. Before continuing, all participants must correctly answer all the questions. Once the experiment begins, talking is not allowed. Any violation of this rule will result in being excluded from the session and not receiving payment. Thank you for your participation.

\section{Appendix 4. Computer screen capture}

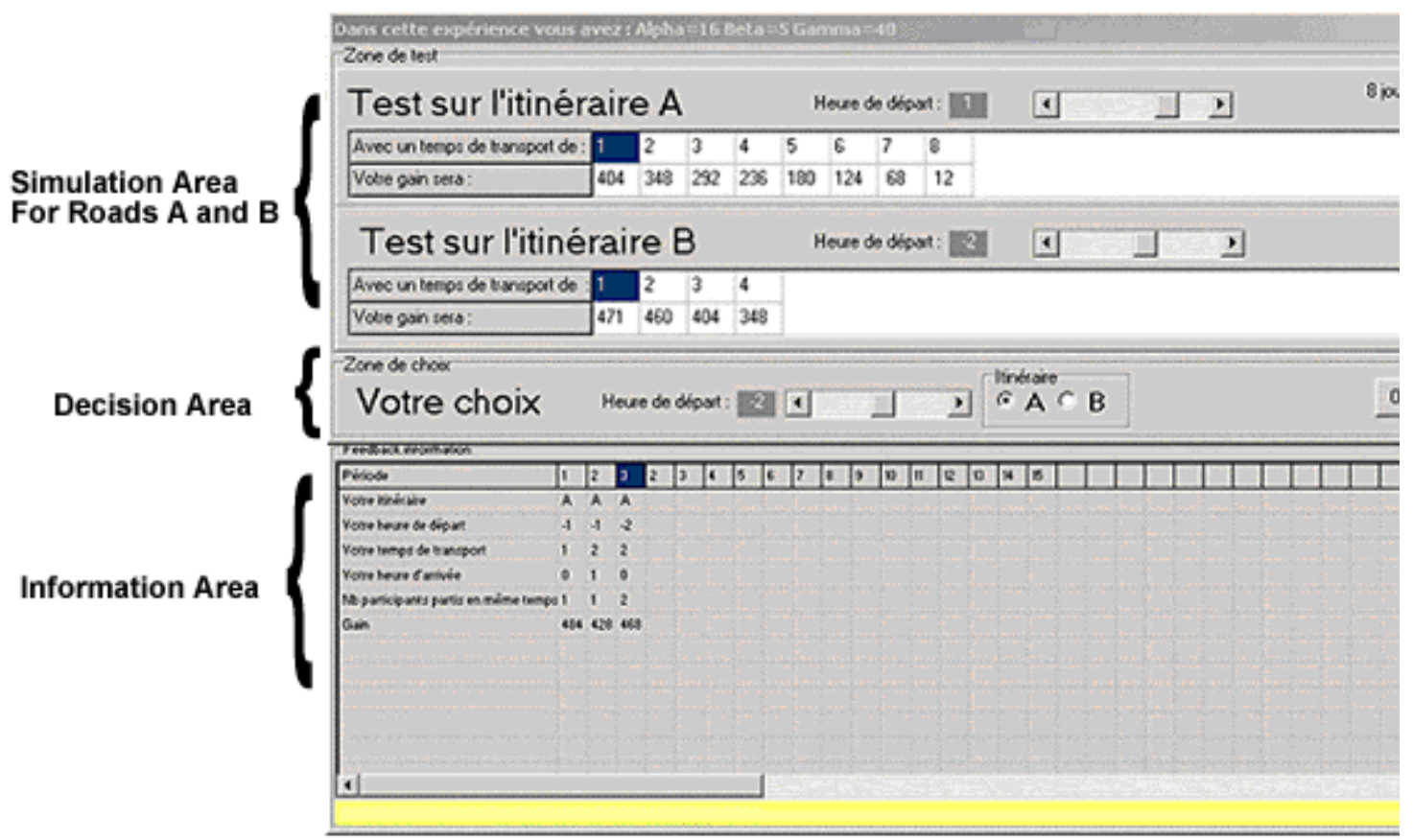

